\title{
Multiple sclerosis and mobility-related assistive technology: Systematic review of literature
}

\author{
Ana Souza, MS; ${ }^{1-2}$ Annmarie Kelleher, MS, OTR/L $;^{1-2}$ Rosemarie Cooper, MPT; ${ }^{1-2}$ Rory A. Cooper, PhD; ${ }^{1-2 *}$ \\ Lisa I. Iezzoni, MD, MSc; ${ }^{3-4}$ Diane M. Collins, PhD $^{1-2}$ \\ ${ }^{1}$ Human Engineering Research Laboratories, Department of Veterans Affairs Pittsburgh Healthcare System, Pitts- \\ burgh, PA; ${ }^{2}$ Department of Rehabilitation Sciences and Technology, University of Pittsburgh, Pittsburgh, PA; ${ }^{3}$ Harvard \\ Medical School, Boston, MA; ${ }^{4}$ Institute for Health Policy, Massachusetts General Hospital, Boston, MA
}

\begin{abstract}
Multiple sclerosis (MS) causes a wide variety of neurological deficits, with ambulatory impairment the most obvious cause of disability. Within 10 to 15 years of disease onset, $80 \%$ of persons with MS experience gait problems due to muscle weakness or spasticity, fatigue, and loss of balance. To facilitate mobility, persons with MS frequently use mobility assistive technology (MAT), such as canes, crutches, walkers, wheelchairs, and scooters. We systematically reviewed the published literature on MAT use among persons with MS. We used electronic reference lists such as Ovid MEDLINE and PubMed to search the literature. We located 50 articles that met the initial criteria of providing good evidence of the types of MAT devices and their benefits for individuals with MS. A limited number of articles with higher levels of evidence was found regarding benefits of MAT use specifically for persons with MS. Evidence-based literature provides the basis for the strongest method of measurable clinical performance; therefore, having a strong research study design is vital to the justification of MAT prescription and reimbursement decisions. However, a paucity of studies with higher levels of evidencebased practice exists.
\end{abstract}

Key words: assistive technology, cane, level of evidence, mobility, multiple sclerosis, quality of life, rehabilitation, scooter, walker, wheelchair.

\section{INTRODUCTION}

Multiple sclerosis (MS), a neurodegenerative disorder of the central nervous system, currently affects approximately 400,000 U.S. residents, with 200 newly diagnosed individuals each week [1-2]. MS causes a wide variety of neurological deficits, with ambulatory impairment as the most obvious cause of disability [3-4]. Within 10 to 15 years of disease onset, 80 percent of persons with MS experience gait problems due to muscle weakness or spasticity, fatigue, and balance impairments [5-7]. To facilitate mobility, persons with MS frequently employ mobility assistive technology (MAT), such as canes, crutches, walkers, wheelchairs, and scooters.

Matching the most appropriate MAT to the needs of a person with MS is vital to his or her daily mobility. Mobility impairments frequently restrict participation in work, family, social, vocational, and leisure activities [8]. Furthermore, persons with MS often experience difficulties

Abbreviations: $\mathrm{AFO}=$ ankle-foot orthosis; $\mathrm{AT}=$ assistive technology; ATP = AT professional; FES = functional electrical stimulation; HFAO = hip flexion assist orthosis; LOE = level of evidence; MAT = mobility AT; MS = multiple sclerosis; PAPAW = power-assist pushrim-activated wheelchair; PHAATE = Policy, Human, Activity, Assistance, Technology, and Environment (model); QOL = quality of life; RET = rehabilitation engineering technologist; $\mathrm{SCI}=$ spinal cord injury.

* Address all correspondence to Rory A. Cooper, PhD; VAPHS, Human Engineering Research Laboratories, 7180 Highland Dr, Bldg 4, 2nd Floor, 151R1-HD, Pittsburgh, PA 15206; 412954-5287; fax: 412-954-5340. Email: rcooper@pitt.edu DOI:10.1682/JRRD.2009.07.0096 
adapting to the changing and progressive nature of mobility loss, frequently marked by exacerbations and remissions [9]. These difficulties can compound relatively high levels of emotional distress, which can exacerbate efforts to accommodate mobility with MAT [10]. A 2008 survey of persons with MS found that 37 percent were too embarrassed to use MAT, while 36 percent reported that they do not use their MAT as much as they should [11].

In addition to standard MAT, new and emerging technologies are undergoing development that could accommodate mobility needs for persons with MS. More studies are exploring the consequences and patterns of MAT use among persons with MS. However, no recent review has examined the growing scientific evidencebased literature about MAT use in MS. We aimed to systematically review the published literature concerning MAT use among persons with MS.

\section{METHODS}

We searched the literature using the electronic reference lists Ovid MEDLINE ${ }^{\circledR}(1950-2008)$, CINAHL ${ }^{\circledR}$ (Cumulative Index to Nursing and Allied Health Literature) (19822008), PubMed (1966-2006), and Scopus (1985-2008). The searches used the following keywords: falls, mobility, multiple sclerosis, cane, walker, wheelchair, assistive technology, and psychological problems. We considered only publications concerning persons with MS with impaired mobility and published in a peer-reviewed journal. After reviewing potential articles, we located 50 that met the initial criteria of providing good evidence of the types of MAT devices and their benefits for persons with MS (details of these studies are presented in the Appendix, available online only).

The articles reviewed in our literature review were evaluated and included according to their levels of evidence (LOEs) and significance, as proposed by Sackett et al. [12]. Their approach is based on evidence-based medicine, which they defined as "a practice of integrating individual clinical expertise with the best available external clinical evidence from systematic research" [12]. To make the process of evaluating published research more efficient, Sackett et al. outlined LOEs and stratified them in order from strongest to weakest:

- I: Evidence is obtained from meta-analysis of multiple, well-designed, controlled studies.
- II: Evidence is obtained from at least one welldesigned experimental study.

- III: Evidence is obtained from well-designed, quasiexperimental studies such as nonrandomized, controlled single-group, pre-post, cohort, time, or matched-case control series.

- IV: Evidence is obtained from well-designed, nonexperimental studies such as comparative and correlational descriptive and case studies.

- V: Evidence is obtained from case reports and clinical examples.

\section{PATTERNS OF MOBILITY IMPAIRMENTS}

\section{Multiple Sclerosis and Risk of Falling}

Persons with MS are particularly predisposed to various impairments, including fatigue and falls due to brain and spinal cord involvement [13-14]. In an observational survey study of 1,089 persons with MS aged 45 to 90 years, Finlayson et al. reported that 52.2 percent of participants had experienced a fall in the past 6 months. Factors associated with an increased risk of falling included being male, having a fear of falling, a deteriorating MS status, balance problems or mobility limitations, and poor concentration [13]. In addition, another survey study found that the absence of weight-bearing activities, unsteady gait, and use of a cane contributed to the multifactorial nature of falls among persons with MS [14]. Common sequelae of falls include fractures, abrasions, lacerations, compromised mobility, loss of confidence in performing tasks, and fear of falling [13]. Therefore, assessment of different aspects of MS-related motor impairments and the accurate determination of factors contributing to falls are necessary for disease management and therapy and for the development of fall prevention programs [14].

\section{Multiple Sclerosis and Mobility Through Ambulation}

Understanding the experiences of mobility loss from the perspective of persons with MS may provide insight into the development of programs, services, and advocacy efforts that support people with MS as they age [1516]. These development efforts must consider several symptoms of MS that influence ambulation: loss of balance, weakness, fatigue, cognitive impairment, fear of falling, spasticity, tremor, and visual impairment [17-18]. In addition, resistance to using appropriate MAT must also be addressed. 
A 2000 literature review conducted by Noseworthy et al. found that even though MS causes a wide variety of neurological deficits, ambulatory impairment is the most common form of resulting disability [5]. Within 15 years of onset, 50 percent of persons with MS will require assistance with walking. Therefore, most persons with MS will require some type of mobility assistance within the course of their disease progression [5]. A survey study conducted in 2001 with 220 participants with MS found similar results to the Noseworthy et al. study, finding that the probability of participants walking 10 to $20 \mathrm{~m}$ without assistance 15 years after diagnosis was 60.3 percent, while the probability of managing to walk a few steps without using a manual wheelchair as a backup was as high as 75.0 percent [19]. The researchers also found that the existence of motor symptoms and advanced age at disorder onset indicated more unfavorable outcomes, but these factors were associated with the progressive course of MS. Baum and Rothschild in 1983 conducted an observational study with 1,145 persons with MS and found that approximately 51 percent of participants reported they needed help with personal mobility both indoors and outdoors [6]. Among study participants, 4 percent reported using crutches, 12 percent walkers, and 40 percent wheelchairs at 13 years after diagnosis [6]. A recent survey-based study conducted with 906 persons with MS also concluded that factors such as being seen by an occupational therapist and the type of MS were the strongest predictors of assistive technology (AT) acquisition [20].

\section{CURRENT ASSISTIVE TECHNOLOGY AND SERVICE DELIVERY}

\section{Mobility Assistive Technology}

When gait difficulties do not respond to therapeutic interventions, MAT devices may be useful tools to enhance mobility [17]. Most persons with MS have mobility restrictions that require MAT devices [9,20-21]. A study with 101 persons with MS indicated that their expectancy of becoming MAT users was as follows: 22.5 percent reported that they expected to be wheelchair-dependent in the short-term (2 years), 38.7 percent in the mid-term (10 years), and 54.0 percent in the longterm ( $>10$ years) [22]. Provision of MAT for persons with MS can potentially diminish activity limitations and participation restrictions, prevent or reduce fatigue by energy conservation and, ultimately, improve quality of life (QOL). MAT includes any device used to maintain or improve mobility [15,23-24]. MAT is also designed to improve functioning, enable successful living at home and in the community, and enhance independence [25].

Therefore, a variety of assistive devices have been used by persons with MS:

1. Ankle-foot orthoses (AFOs) have been an effective solution for compensating weakness, restoring energy, and helping to control unstable knee and ankle musculature. AFOs are also used for foot drop, a condition in which the individual cannot clear his or her toes in the swing-through phase of mobility, which affects normal gait [26]. AFOs can be made from composite materials or plastics with two different mechanisms: rigid or articulated. Recently, carbon-fiber AFOs have become popular among persons with MS. They generally come in two styles: (1) an anterior shell with a medial or lateral upright component that creates knee stabilization, preventing knee extension, and that reduces foot drop and (2) a posterior shell that compensates for ankle dorsiflexor weakness while returning energy by providing a spring effect during toe push off, consequently helping with toe clearance during the swing part of gait. Negative factors associated with AFOs are limited ankle and knee mobility during kneeling, running, or stooping.

2. Functional electrical stimulation (FES), which has been used for treatment of muscles deprived of nervous control, provides muscle contraction and functional movement [26]. For persons with MS, FES has been a useful tool for foot drop, balance, and walking training during rehabilitation treatment; advanced technology has enabled a new system unit with wireless communication. However, the decision between an AFO and/or different models of FES is ultimately clinical and needs to be made by the potential user, physical therapist, and physician together.

3. Hip flexion assist orthoses (HFAOs) are another option for persons with MS who do not effectively ambulate despite the use of an AFO or FES. The HFAO is indicated for persons with unilateral lowerlimb weakness in the hip and knee flexors along with the ankle and dorsiflexor muscles [26].

4. Canes assist ambulation by maintaining the even distribution of weight on the hips that is characteristic of a normal gait. Canes are also beneficial when walking is only mildly unstable, reducing walking effort and risk of falls when compared with AFOs and HFAOs [26]. 
Several types of canes are available, including singlelegged canes and "quad" canes, which have a broad base of support and can remain upright independently so they do not become a tripping hazard.

5. Crutches are also used to aid with ambulation by helping with balance, widening the base of support, and decreasing weight bearing on a single lower limb. Crutches provide more balance than canes during walking and are indicated for people who need bilateral support and have good upper-limb control [26].

6 . Walkers and/or wheeled walkers (rollators) are indicated for persons with moderate deficits and provide increased stability as a result of the walker's larger footprint compared with a cane or crutches. In addition, they can be purchased with wheels, brakes, and modified handgrips to aid in function and safe use [26]. Further, to assist with fatigue, some walkers are equipped with seats for short rest periods during ambulation.

7. Manual wheelchairs provide a more stable wheeled option while still providing some level of physical activity [26]. In addition, manual wheelchairs can be used part-time or as a primary exclusive mobility option for persons who are experiencing balance difficulties and frequent falls.

8. Power-assist pushrim-activated wheelchairs (PAPAWs) are manual wheelchairs with a force/moment-sensing pushrim, which provides assistance with wheelchair propulsion while requiring less physical strain. For people with MS, PAPAWs may prove to be a good compromise between the fatigue caused by propelling among manual wheelchair users and the lack of exercise among power wheelchair users [26].

9. Scooters are a popular mode of powered mobility among persons with MS. Some users prefer a scooter to a manual wheelchair, since upper limb fatigue is not an issue. However, scooters are often less desirable than power wheelchairs because of their lack of stability during turns and limited seating system options to accommodate users with specific seating needs, as seen in progressive disorders such as MS [26-27]. Scooters are available in two types: three- and fourwheeled. The four-wheeled scooters typically offer more device stability than the three-wheeled scooters, but as a result, they are difficult to maneuver and heavier and thus more difficult to transport.

10. Power wheelchairs should not only be considered a mobility option for advanced stages but should also be recommended as a MAT option to address fatigue, a hallmark symptom of MS [14,25,28-29]. In contrast to scooters, power wheelchairs permit power seating system upgrades that may be indicated as the client progresses and are configured in different types of driving base designs. Three main power wheelchair base options are available: rear-wheel, mid-wheel, and front-wheel drives [25].

Among the various MAT options, manual wheelchairs $(60 \%)$ have been reported as the most common MAT used by persons with MS, followed by canes and crutches (44\%), walkers (39\%), and power wheelchairs (8\%) [20]. In an observational study, Baum and Rothschild have also shown that a greater number of persons use wheelchairs (40\%) than walkers/canes (12\%), leg braces (6\%), and crutches (4\%) [6]. In a recent retrospective study, manual wheelchairs (33\%) were again the most prescribed devices, followed by power wheelchairs (13\%), walkers (6\%), braces (6\%), and canes (2\%) [30]. The use of wheelchairs has been positively correlated to the duration of the disease, age, and awareness of the diagnosis $[6,30]$.

Characteristics of ambulatory persons with MS who transitioned to a wheeled mobility device were compared with those of persons with spinal cord injury (SCI) and investigated by Ambrosio et al. in a retrospective study [31]. Participants with MS were not able to ambulate at functional speeds and had sedentary activity levels. Further, the quality of wheeled mobility devices recommended to persons with MS was inferior to that of devices issued to persons with SCI. In another surveybased study by Perks et al., 59 percent of wheelchair users stated that they did not feel their wheelchairs met their mobility needs and therefore they had difficulty navigating within different environments [32]. In addition, a 2002 literature review study by Fay and Boninger investigated the efficacy of manual wheelchair propulsion in full-time manual wheelchair users with MS [33]. Results showed that persons with MS were unable to maintain a functional speed of wheelchair propulsion when compared with a control group of persons with SCI and a group of persons with no disability. Kinetic analyses revealed that with propulsive stroke of the manual wheelchairs, persons with MS applied a force in the opposite direction of forward propulsion, essentially working against themselves every time they pushed their chairs, leading to increased energy expenditure during wheelchair propulsion. This higher energy expenditure is 
a significant problem for this population, for whom fatigue is a major limiting factor [33]. Thus, prescription of a powered mobility device, such as a scooter or power wheelchair, would be more appropriate than a manual wheelchair, depending on many factors such as client diagnosis, comorbid conditions, living environment, and use of transportation. Users of MAT devices frequently view mobility devices as a symbol of loss of function or greater disability. Despite this fact, transition from manual to power wheelchairs has been reported to enhance users' occupational performance, with increased feelings of competence, adaptability, and self-esteem [34].

Given the scarce research on AT for persons with MS and its importance on their activities of daily living, healthcare professionals and researchers have had to refer to work done on other populations with disabilities, such as SCI or cerebral palsy [33]. Persons who cannot walk and rely primarily on a combination of manual and power wheelchairs are more likely to be active in the community than those with these disabilities but who can walk and, therefore, use an ambulation aid and manual wheelchair combined [35]. Power wheelchairs allowed persons with MS to minimize the effort needed to ambulate or propel a manual wheelchair, resulting in conserved energy for use with other activities [35-36]. Having an appropriate mobility device can significantly influence how a person with a disability perceives life [34].

Power wheelchairs with different seating systems, such as tilt-in-space and recline, help persons with MS rest comfortably in their chairs during the day without needing to return to bed or transfer to a static chair [36]. In a descriptive study, Dewey et al. concluded that people with severe MS symptoms preferred to be out of bed as much as possible, and thus, the prescription of tilt-inspace options should be highly considered by clinicians and consumers looking for power wheelchairs despite their cost [36]. A prospective study conducted by Ding et al. examined the use of tilt-in-space and recline among nondisabled persons, and their results showed that the most favorable angles with maximum pressure reduction were $45^{\circ}$ of tilt and $120^{\circ}$ of recline [37]. In addition, the authors also reported that a combination of tilt and backrest recline achieved greater pressure reduction than tilt alone. Therefore, power-seat functions positively affect users' QOL because they allow users to remain in their chairs longer, decrease the risk of pressure sores, conserve energy, access a variety of environments, and participate in more activities during the day [38]. In addition, tilt-in-space decreases the user's risk of pressure sores, especially in advanced cases of MS in which the person has decreased pressure-relief ability [35-36]. The use of power-seat functions proves to be essential in helping power wheelchair users be more comfortable, with less need for transfers throughout the day, especially among persons with progressive diagnoses [29].

Caution should be taken in the prescription of MAT devices, especially for persons with MS; if the prescription does not meet the user's needs, the MAT prescribed might not be used and instead abandoned. A retrospective study conducted by Verza et al. in 2006 found that AT devices were abandoned because of worsening in physical status (36.4\%), followed by nonacceptance of the device by the user (30.3\%), inappropriateness (24.2\%), and insufficient/lack of information and training (9.0\%) [30]. A reason for this device abandonment could be a change in medical condition; in addition, functional ability is a strong factor influencing abandonment of AT [25]. Unlike with other diagnoses, MAT for people with MS may not be a long-term solution because of the progressive nature of the disorder. MAT abandonment is costly in both financial terms and outcomes achievement, regardless of whether the abandoned equipment is high or low technology [25]. Device abandonment could be reduced if consumers were actively involved from the start of the MAT service-delivery process. A better understanding of how and why persons decide to accept or reject different types of MAT is critical to improving these persons' QOL [25].

\section{Mobility Assistive Technology Use and Service Delivery}

In advanced stages of MS, several interventions can provide assistance with independence to the individual, such as (1) provision, education, and instruction in use of assistive devices (walking aids, power/manual wheelchairs, and car adaptations); (2) education and instruction about compensatory strategies to accomplish an activity (safe transfers); and (3) environmental modifications (ramps, lifts, wider doors, level access showers, bath aids, and environmental control systems) $[9,20]$.

MAT must serve as an interface between the person with a disability and the activity the person chooses to perform and must promote reintegration into community life [39]. Services models are used as guidelines to provide a comprehensive conceptual model representing factors to be considered in the design of an AT device or the development of a service-delivery program that not only 
meets user needs but also is in accordance with policy regulations [39]. Therefore, researchers have been developing a comprehensive model of service delivery that includes those factors and improves not only service delivery but also policy regulations.

Researchers from the University of Pittsburgh recently developed a new service delivery model called the Policy, Human, Activity, Assistance, Technology, and Environment (PHAATE) model. This model incorporates policy, human, activity, assistance, technology, and environment into service delivery of AT [39]. The PHAATE model was developed to create a comprehensive model representing factors that should be considered in the design of AT devices or in the actual development of a service-delivery program. When prescribing AT, clinicians must prioritize each individual's medical benefit and consider the reimbursement policy to avoid denial of reimbursement due to lack of well-documented letters of medical necessity. However, the policy should not influence or dictate the final clinical recommendation for the most appropriate MAT device. The environment and context should be considered during the service-delivery process, because people perform activities in a variety of environments [39]. One problem of AT provision lies in the paucity of AT outcome studies, partially due to inadequate funding support for research studies or lack of understanding of the need for specialized clinical expertise, especially among insurers and nonrehabilitation medical professionals [39].

Studies investigating service-delivery models in countries such as Ireland and Canada showed that the development of a client-focused, social, and participatory AT service-delivery model achieves the best results for people with disabilities and their caregivers [40]. Another observational study was conducted in 2005 by Ripat and Booth to identify key characteristics of the AT service-delivery model preferred by the various Canadian stakeholders [41]. When prescribing AT, clinicians should focus on persons' medical necessity and their specific needs during the decision-making process as well as when choosing appropriate AT devices. Based on these study results, recommendations for service delivery were proposed for future use in other AT clinics. These study results may help in the development of funding guidelines, the support of the importance of AT in enabling meaningful activities, and the examination of current service delivery in different contexts. Participation of the end user needs to be considered throughout the entire AT process. The evaluation process should address the user's skill, goals, abilities, supports, resources, and context [40-41].

AT is, therefore, best delivered with a team approach, including AT professionals (ATPs) and rehabilitation engineering technologists (RETs) working in cooperation with qualified physicians, all focused on the needs of the end users. For this reason, the Rehabilitation Engineering and Assistive Technology Society of North America provides the ATP and RET credentials to identify knowledgeable clinicians, suppliers, and engineers [42]. These efforts and research studies on how to improve AT service delivery may decrease AT abandonment and consequently increase users' satisfaction, community participation, and QOL.

\section{New and Emerging Mobility Assistive Technologies}

In a 2007 prospective research study, Sawatzsky et al. investigated the use of the Segway ${ }^{\circledR}$ Personal Transporter device (Segway Inc; Bedford, New Hampshire), another powered mobility device for persons with limited ambulatory ability, such as people with MS or lower-limb amputations [43]. Segway devices are described as "the first selfbalancing, electric-powered transportation devices." The rider stands on a small platform supported $20 \mathrm{~cm}$ off the ground by two parallel wheels and holds onto the handlebars. A twist grip on the left bar is used to steer the device. When the rider moves forward, the Segway moves forward; when the rider leans back, it moves back or stops. The Segway is marketed as a revolutionary device that requires no special skills and that "virtually anyone can use." In this particular study, the authors found that the Segway was a useful device for a wide range of disabilities (e.g., MS, SCI, amputation) and it may also increase personal mobility for some people with functional limitations. Therefore, it would enable people with functional limitations to become more involved in meaningful activities and, hence, increase their QOL [43].

For persons with difficulty operating a mobility device because of decreased physical strength or environmental accessibility barriers, a new concept has been developed to accommodate those issues: the Independence iBOT 3000 mobility system (Independence Technology, Johnson \& Johnson; New Brunswick, New Jersey) [44]. The iBOT was recently developed with the purpose of overcoming many of the limitations of currently available mobility devices [44]. The iBOT has a computer system designed to provide a dynamic balance reaction in the fore-aft direction and has five different operating functions: (1) standard (similar to a traditional power wheelchair), (2) four-wheel 
(four-wheel drive for outdoor mobility including curb climbing), (3) balance (two-wheel drive, dynamically balanced on two wheels for mobility at the elevated height of a standing person), (4) stair-climbing (rotation of the wheel clusters to allow "stepping up" one stair at a time), and (5) remote (nonoccupied mobility device) [44]. Even though the iBOT is a good mobility option for persons with ambulatory impairment, it is an expensive device with funding unavailable by Medicare; hence, it is no longer available on the market.

Another option in power wheelchairs designed for indoor and outdoor use and stair climbing is called the TopChair (Hmc2développement; Toulouse-Montrabé, France) [45]. This power wheelchair comprises combined wheels and a caterpillar track. The TopChair was tested in France among 25 persons with SCI, and results showed that all participants were able to successfully operate the power wheelchair indoors and outdoors. Due to its electromechanic property and caterpillar tracks, the TopChair is a little bulkier and heavier than other power wheelchairs with similar functions. However, no studies have evaluated the benefits of the TopChair among persons with MS.

Even though new technologies have been developed recently to enhance mobility and community participation, a clinician must consider many factors when trying to match a person with an assistive device [30]. Using an assistive device for mobility could vary in two ways: fulltime use or part-time use, depending on level of disability and functional characteristics [30]. Evaluating and understanding the pros and cons of each device, either with a new design and features or with a device already on the market, are vital when MATs are prescribed. The successful use of each MAT will be based on the interaction of knowledge of the disorder stage by the rehabilitation professional and willingness of the person with MS to accept and use what is suggested.

\section{PSYCHOSOCIAL FACTORS AND MOBILITY ASSISTIVE TECHNOLOGY USE}

\section{Psychological Aspects of Multiple Sclerosis}

Emotional distress is higher among persons with MS than with other chronic illnesses and is three times more common in persons with MS than in the general population [10]. Contributing factors to high emotional distress rates in persons with MS include the uncertainty and unpredictabil- ity of symptoms and disability over time. Results from secondary analyses of a survey-based study by Gulick suggested that the presence of emotional and financial support together with coping strategies explain how persons with MS can enhance their performance in everyday activities, including personal care, mobility, recreation, socializing, and intimacy, despite the presence of emotional distress arising from this disabling chronic disorder [10]. Support groups are options for persons with MS who are either recently diagnosed or having problems dealing with or adjusting to their diagnosis of MS. These groups are designed to take people from the initial emotional response of acknowledging their diagnoses to a different view of how to cope with and practically manage their symptoms [46]. The participation of care partners becomes particularly important at these times, mainly because they will then learn from other families how to best support their loved ones with MS [47]. The psychological aspects of MS have been reported not only among adults but also among children. Interestingly, the psychosocial difficulties seen among children and adolescents with MS have the same manifestations as adults [48]. These manifestations affect the persons' self-image, role functioning, mood, and cognition not only in school but also at work, in their interpersonal relationships, and during treatment compliance. Among older adults, fear of the future is the major concern, which enhances the fear of experiencing future losses of mobility and independence, becoming a burden on caregivers and, ultimately, moving into a nursing home [49].

Another important factor in the psychological aspect of persons with MS is the use of an AT device, especially for mobility, which has a great influence on the activities of daily living and independence of persons with MS. Inability to go out or difficulty going out in the community increases frustration and dependence on others, consequently increasing the probability of depression. A 2001 survey-based study by Buning et al. investigated the impact of transition from manual to power wheelchairs and its influence on the persons' occupational performance and psychosocial coping with regard to this transition [34]. The authors found that changing from a manual to a power wheelchair increased participants' occupational performance in daily life; moreover, their satisfaction with using a power wheelchair increased their competence, adaptability, and self-esteem [34]. Even though the study population was small $(n=8)$, these results suggest that the use of power wheelchairs may positively influence not only people with chronic disabilities, such as SCI and traumatic brain injury, 
but also people with progressive conditions, such as MS and muscular dystrophy. Despite how persons with MS think of their disability while using MAT devices such as power wheelchairs, these devices can contribute to their resilience during mobility-related activities of daily living by restoring their ability to perform actions, tasks, and projects, which support occupational and role performance [34].

In addition to finding the best option when prescribing AT devices, rehabilitation professionals must equally emphasize the influence of a good interaction between persons with MS and their family [25-46,48-50]. Having a family member with MS may affect the overall family dynamics, whether the person is a child or an adult [48]. Poor communication between persons with MS and their family may jeopardize the decision to acquire an appropriate AT device. In cases in which only family members are available to decide on an AT device, their decision could have detrimental effects on the psychosocial wellbeing of persons with MS if they feel that they do not have control over or input into the kind of equipment obtained [50]. Persons with MS and their family should discuss and agree on the risks and benefits of the AT to be used to maintain a supportive environment with good adaptation to the new device [51]. An open relationship between persons with MS, their family members, and rehabilitation professionals involved in prescribing an AT device will result in better outcomes [34,50].

Pain is an important factor influencing psychosocial functioning. In a study conducted among veterans with MS, increased fatigue, poor general health, and greater depression symptom severity were significantly associated with higher levels of pain. Therefore, pain should be treated aggressively to minimize functional impairment [51]. Also, preventing pain due to extended seating in wheeled mobility devices should be addressed.

\section{Mobility Impairment and Quality of Life}

A survey-based study conducted with 412 persons with MS showed that more than 50 percent of persons with long-standing MS required assistance both in and out of their homes [14]. In addition, factors increasing the percentage of people who needed assistance included longer MS duration, diagnosis at an older age, and the individual's acknowledgment of the diagnosis [6,9]. Reduced mobility has been associated with built environmental barriers, difficulty in completion of daily activities, restricted participation in life tasks [15-16], and perceived reduced QOL and community participation [23,52]. In 2002, a literature review study by Fay and Boninger found that QOL was closely correlated with mobility [33]. A 2007 retrospective study among 196 persons with MS showed that persons with decreased physical activity also had reduced QOL. The same study concluded that barriers in the built environment influenced physical activity levels and community participation [47]. An accessible environment not only promotes high levels of physical activity but also results in increased community participation, particularly among persons with MS.

Significantly decreased mobility and self-reported QOL in the MS population have been highlighted as important intervention needs $[6,24,47]$. Over time, persons with MS experience reductions in health status and physical function [53]. In addition, persons with chronic progressive MS experience more activity limitations than do persons with relapsing-remitting and benign types of MS. Fatigue, weakness, balance impairments, spasticity, tremors, and speech and swallowing problems are the most troublesome MS symptoms that impact the activity performance of persons with MS [53-54]. Hence, the resulting impaired ambulation is an important contributor to disability and decreased QOL in persons with MS [23,55].

\section{CONCLUSIONS}

Beside the physical, psychological, and economic impact of MS on patients and family members, this disorder causes a wide variety of neurological deficits, of which ambulatory impairment is the first symptom and the most common form of disability [4]. Common symptoms of MS include fatigue, weakness, spasticity, ataxia, somatosensory symptoms such as visual impairment, and other impairments of cranial nerves and brain stem structures [19].

The type, severity, and frequency of symptoms determine MS progression and the potential need for MAT devices. The unpredictable nature of MS is a constant challenge for not only persons with MS but also their family and friends. The possibility of losing the ability to walk increases the stress and psychological aspects of being diagnosed with MS. Therefore, relying on an assistive device for mobility becomes very important to all persons with MS.

One of the biggest challenges for rehabilitation professionals and persons with MS is finding a mobility device that meets the users' needs and maintains or increases community participation [52]. Being able to remain active in the community and also keep their jobs are some of the biggest challenges for persons with MS. Independence is just one of the important factors that must be considered 
when MAT is being prescribed. Other factors that require consideration are degree of fatigue, activities that the person with MS wants to do, context in which the device will be used, how the device will be funded, and user acceptance of the device. Many MAT options are available on the market. The options vary from AFOs, canes, and walkers to power wheelchairs with many different functions. It is important to note that pursuing MAT devices is a process that involves the person with MS and his or her rehabilitation professional team and family members. To be successful, the MAT device must improve the overall QOL of the person with MS.

Throughout our literature review, we observed that a limited number of articles with higher LOEs were found regarding the benefits of MAT use specifically for persons with MS. There is a paucity in studies with higher LOE-based practice, and most of the articles found were LOE IV $(n=32)$ and V $(n=15)$, followed by III $(n=2)$ and II $(n=1)$. Evidence-based practice is the strongest method of measurable clinical performance; therefore, having a strong study design is the best way to justify prescription and reimbursement decisions. Future quantitative studies should be conducted to provide a better understanding of the benefits of appropriate MAT for persons with MS. In addition, assessing the QOL of potential users before and after MAT acquisition might be another way to understand and enhance the benefits of MAT for persons with MS.

\section{ACKNOWLEDGMENTS}

\author{
Author Contributions: \\ Study concept and design: A. Kelleher, R. Cooper, R. A. Cooper, \\ L. I. Iezzoni, D. M. Collins. \\ Acquisition of data: A. Souza. \\ Drafting of manuscript: A. Souza, A. Kelleher, R. Cooper, D. M. Collins. \\ Critical revision of manuscript for important intellectual content: \\ A. Souza, A. Kelleher, R. Cooper, R. A. Cooper, L. I. Iezzoni. \\ Administrative, technical, or material support: R. A. Cooper, \\ L. I. Iezzoni. \\ Study supervision: R. A. Cooper.
}

Financial Disclosures: The authors have declared that no competing interests exist.

Funding/Support: This material was based on work supported by the Massachusetts General Hospital National Multiple Sclerosis Society (contract No. HC 0079T) and is the result of work supported with resources and the use of facilities at the Human Engineering Research Laboratories, Department of Veterans Affairs Pittsburgh Healthcare System.

\section{REFERENCES}

1. Ramsaransing GS, De Keyser J. Benign course in multiple sclerosis: A review. Acta Neurol Scand. 2006;113(6):359-69. [PMID: 16674602]

DOI:10.1111/j.1600-0404.2006.00637.x

2. National Multiple Sclerosis Society. FAQs about MS [Internet]. New York (NY): National Multiple Sclerosis Society; 2008 [cited 2010 Mar 5]. Available from: http://www.nationalmssociety.org/about-multiple-sclerosis/ what-we-know-about-ms/FAQs-about-MS/index.aspx/.

3. Pediatric MS. Pediatric MS \& acquired demyelinating conditions [Internet]. Buffalo (NY): Jacobs Neurological Institute of the University of Buffalo; 2008 [cited 2008 Jun 20]. Available from: http://www.pedsms.org/adc.html/.

4. Whetten-Goldstein K, Sloan FA, Goldstein LB, Kulas ED. A comprehensive assessment of the cost of multiple sclerosis in the United States. Mult Scler. 1998;4(5):419-25. [PMID: 9839302]

5. Noseworthy JH, Lucchinetti C, Rodriguez M, Weinshenker BG. Multiple sclerosis. N Engl J Med. 2000;343(13):938-52. [PMID: 11006371] DOI:10.1056/NEJM200009283431307

6. Baum HM, Rothschild BB. Multiple sclerosis and mobility restriction. Arch Phys Med Rehabil. 1983;64(12):591-96. [PMID: 6661022]

7. Pittock SJ, Mayr WT, McClelland RL, Jorgensen NW, Weigand SD, Noseworthy JH, Weinshenker BG, Rodriguez M. Change in MS-related disability in a population-based cohort: A 10-year follow-up study. Neurology. 2004;62(1): 51-59. [PMID: 14718697]

8. Assistive Technology Act of 1998, 105 U.S.C. Sect. 508 (1998).

9. Cattaneo D, De Nuzzo C, Fascia T, Macalli M, Pisoni I, Cardini R. Risks of falls in subjects with multiple sclerosis. Arch Phys Med Rehabil. 2002;83(6):864-7. [PMID: 12048669]

10. Gulick EE. Emotional distress and activities of daily living functioning in persons with multiple sclerosis. Nurs Res. 2001;50(3):147-54. [PMID: 11393636] DOI:10.1097/00006199-200105000-00004

11. Harris Interactive. Key findings from two new multiple sclerosis surveys [Internet]. New York (NY): National MS Society and Acorda Therapeutics; 2008 [cited 2008 Mar 30]. Available from: http://www.nationalmssociety.org/ news/news-detail/download.aspx?id=1018/.

12. Sackett DL, Straus SE, Richardson WS, Rosenberg W, Haynes RB. Evidence-based medicine: How to practice and teach EBM, 2nd ed. Edinburgh (UK): Churchill-Livingstone, 2000.

13. Finlayson ML, Peterson EW, Cho CC. Risk factors for falling among people aged 45 to 90 years with multiple sclerosis. Arch Phys Med Rehabil. 2006;87(9):1274-79. 
JRRD, Volume 47, Number 3, 2010

\section{[PMID: 16935067]}

DOI:10.1016/j.apmr.2006.06.002

14. Gulick EE, Yam M, Touw MM. Work performance by persons with multiple sclerosis: Conditions that impede or enable the performance of work. Int J Nurs Stud. 1989; 26(4):301-11. [PMID: 2613450] DOI:10.1016/0020-7489(89)90017-5

15. Blake DJ, Bodine C. An overview of assistive technology for persons with multiple sclerosis. J Rehabil Res Dev. 2002;39(2):299-312. [PMID: 12051472]

16. Finlayson M, Van Denend T. Experiencing the loss of mobility: Perspectives of older adults with MS. Disabil Rehabil. 2003;25(20):1168-80. [PMID: 14534060] DOI:10.1080/09638280310001596180

17. Peterson EW, Cho CC, Finlayson ML. Fear of falling and associated activity curtailment among middle aged and older adults with multiple sclerosis. Mult Scler. 2007;13(9): 1168-75. [PMID: 17881391] DOI:10.1177/1352458507079260

18. Klewer J, Pöhlau D, Nippert I, Haas J, Kugler J. Problems reported by elderly patients with multiple sclerosis. J Neurosci Nurs. 2001;33(3):167-71. [PMID: 11413662]

19. Myhr KM, Riise T, Vedeler C, Nortvedt MW, Grønning M, Midgard R, Nyland HI. Disability and prognosis in multiple sclerosis: Demographic and clinical variables important for the ability to walk and awarding of disability pension. Mult Scler. 2001;7(1):59-65. [PMID: 11321195]

20. Finlayson M, Guglielmello L, Liefer K. Describing and predicting the possession of assistive devices among persons with multiple sclerosis. Am J Occup Ther. 2001;55(5): 545-51. [PMID: 14601815]

21. Miller A, Coyle PK. Clinical features of multiple sclerosis. Continuum. 2004;10:38-73.

22. Janssens AC, De Boer JB, Van Doorn PA, Van der Ploeg HM, Van der Meché FG, Passchier J, Hintzen RQ. Expectations of wheelchair-dependency in recently diagnosed patients with multiple sclerosis and their partners. Eur J Neurol. 2003;10(3):287-93. [PMID: 12752403] DOI:10.1046/j.1468-1331.2003.00583.x

23. Aronson KJ. Quality of life among persons with multiple sclerosis and their caregivers. Neurology. 1997;48(1):74-80. [PMID: 9008497]

24. Lankhorst GJ, Jelles F, Smits RC, Polman CH, Kuik DJ, Pfennings LE, Cohen L, Van der Ploeg HM, Ketelaer P, Vleugels L. Quality of life in multiple sclerosis: The Disability and Impact Profile (DIP). J Neurol. 1996;243(6):469-74. [PMID: 8803821] DOI:10.1007/BF00900502

25. Scherer MJ. Outcomes of assistive technology use on quality of life. Disabil Rehabil. 1996;18(9):439-48.

[PMID: 8877302] DOI:10.3109/09638289609165907
26. Sutliff MH. Team focus: Physical therapist. Int J Multi Scler Care. 2008;10(4):127-32.

27. Kraskowsky LH, Finlayson M. Factors affecting older adults' use of adaptive equipment: Review of the literature. Am J Occup Ther. 2001;55(3):303-10. [PMID: 11723971]

28. Freeman JA. Improving mobility and functional independence in persons with multiple sclerosis. J Neurol. 2001; 248(4):255-59. [PMID: 11374088]

DOI:10.1007/s004150170198

29. Lacoste M, Weiss-Lambrou R, Allard M, Dansereau J. Powered tilt/recline systems: Why and how are they used? Assist Technol. 2003;15(1):56-68. [PMID: 14760982]

30. Verza R, Carvalho ML, Battaglia MA, Uccelli MM. An interdisciplinary approach to evaluating the need for assistive technology reduces equipment abandonment. Mult Scler. 2006;12(1):88-93. [PMID: 16459724] DOI:10.1191/1352458506ms1233oa

31. Ambrosio F, Boninger ML, Fitzgerald SG, Hubbard SL, Schwid SR, Cooper RA. Comparison of mobility device delivery within Department of Veterans Affairs for individuals with multiple sclerosis versus spinal cord injury. J Rehabil Res Dev. 2007;44(5):693-701. [PMID: 17943681] DOI:10.1682/JRRD.2006.02.0016

32. Perks BA, Mackintosh R, Stewart CP, Bardsley GI. A survey of marginal wheelchair users. J Rehabil Res Dev. 1994; 31(4):297-302. [PMID: 7869277]

33. Fay BT, Boninger ML. The science behind mobility devices for individuals with multiple sclerosis. Med Eng Phys. 2002;24(6):375-83. [PMID: 12135646$]$ DOI:10.1016/S1350-4533(02)00037-1

34. Buning ME, Angelo JA, Schmeler MR. Occupational performance and the transition to powered mobility: A pilot study. Am J Occup Ther. 2001;55(3):339-44.

[PMID: 11723976]

35. Ambrosio F, Boninger ML, Fitzgerald S, Liu B, Mapa M, Collins DM. Mobility device as a determinant of social participation in persons with multiple sclerosis. Proceedings of the RESNA 26th International Annual Conference. 2003. Atlanta, Georgia. Arlington (VA): RESNA; 2004.

36. Dewey A, Rice-Oxley M, Dean T. A qualitative study comparing the experiences of tilt-in-space wheelchair use and conventional wheelchair use by clients severely disabled with multiple sclerosis. Br J Occup Ther. 2004;67(2):65-74.

37. Ding D, Cooper RA, Cooper R, Kelleher A. Monitoring seat feature usage among wheelchair users. In: Engineering in Medicine and Biology Society, 2007. 29th Annual International Conference of the IEEE. 2007 Aug 22-26. Lyon, France. Los Alamitos (CA): IEEE; 2007; p. 4364-67.

38. Devitt R, Chau B, Jutai JW. The effect of wheelchair use on quality of life of persons with multiple sclerosis. Occup Ther Health Care. 2003;17:63-79. DOI:10.1300/J003v17n03 05 
39. Cooper RA, Ohnabe H, Hobson DA. An introduction to rehabilitation engineering. Boca Raton (FL): Taylor \& Francis; 2007. p. 444.

40. Craddock G, McCormack L. Delivering an AT service: A client-focused, social and participatory service delivery model in assistive technology in Ireland. Disabil Rehabil. 2002;24(1-3):160-70. [PMID: 11827150]

DOI:10.1080/09638280110063869

41. Ripat J, Booth A. Characteristics of assistive technology service delivery models: Stakeholder perspectives and preferences. Disabil Rehabil. 2005;27(24):1461-70. [PMID: 16421071] DOI:10.1080/09638280500264535

42. Rehabilitation Engineering and Assistive Technology Society of North America (RESNA) [Internet]. [cited 2008 Jul 10]. Arlington (VA): RESNA. Available from: http://www.resna.org/.

43. Sawatzky B, Denison I, Langrish S, Richardson S, Hiller K, Slobogean B. The Segway Personal Transporter as an alternative mobility device for people with disabilities: A pilot study. Arch Phys Med Rehabil. 2007;88(11):1423-28. [PMID: 17964882]

DOI:10.1016/j.apmr.2007.08.005

44. Uustal H, Minkel JL. Study of the Independence IBOT 3000 Mobility System: An innovative power mobility device, during use in community environments. Arch Phys Med Rehabil. 2004;85(12):2002-10. [PMID: 15605340] DOI:10.1016/j.apmr.2004.04.044

45. Laffont I, Guillon B, Fermanian C, Pouillot S, EvenSchneider A, Boyer F, Ruquet M, Aegerter P, Dizen O, Lofaso F. Evaluation of a stair-climbing power wheelchair in 25 people with tetraplegia. Arch Phys Med Rehabil. 2008;89(10):1958-64. [PMID: 18929024]

DOI:10.1016/j.apmr.2008.03.008

46. Simsarian J, Sanders C. An evolving approach to patient support programs for MS. MS Exchange. 2008;12(2):1-2.

47. Doerksen SE, Motl RW, McAuley E. Environment correlates of physical activity in multiple sclerosis: A cross-sectional study. Int J Behav Nutr Phys Act. 2007;4:49.

[PMID: 17922918]

DOI:10.1186/1479-5868-4-49

48. MacAllister WS, Boyd JR, Holland NJ, Milazzo MC, Krupp LB; International Pediatric MS Study Group. The psychosocial consequences of pediatric multiple sclerosis. Neurology. 2007;68(16 Suppl 2):S66-69. [PMID: 17438240]

49. Finlayson M. Concerns about the future among older adults with multiple sclerosis. Am J Occup Ther. 2004;58(1):54-63. [PMID: 14763636]

50. Boss TM, Finlayson M. Responses to the acquisition and use of power mobility by individuals who have multiple sclerosis and their families. Am J Occup Ther. 2006;60(3): 348-58. [PMID: 16776403]

51. Osborne TL, Turner AP, Williams RM, Bowen JD, Hatzakis M, Rodriguez A, Haselkorn JK. Correlates of pain interference in multiple sclerosis. Rehabil Psychol. 2006; 51(2):166-74. DOI:10.1037/0090-5550.51.2.166

52. Scherer MJ, Glueckauf R. Assessing the benefits of assistive technologies for activities and participation. Rehabil Psychol. 2005;50(2):132-41. DOI:10.1037/0090-5550.50.2.132

53. Finlayson M, Impey, MW, Nicolle C, Edwards J. Self-care, productivity and leisure limitations of people with multiple sclerosis. Can J Occup Ther. 1998;65(5);299-308.

54. Solari A, Ferrari G, Radice D. A longitudinal survey of self-assessed health trends in a community cohort of people with multiple sclerosis and their significant others. J Neurol Sci. 2006;243(1-2):13-20. [PMID: 16380136]

DOI:10.1016/j.jns.2005.11.005

55. Månsson E, Lexell J. Performance of activities of daily living in multiple sclerosis. Disabil Rehabil. 2004;26(10):576-85. [PMID: 15204511$]$ DOI:10.1080/09638280410001684587

Submitted for publication July 10, 2009. Accepted in revised form January 20, 2010. 
